\title{
Adhesion of the powder flame sprayed coatings using Fe-Cr-Co-Mo powder
}

\section{Keywords:}

powder flame spraying;

coating;

adhesion strength;

surface modification

\begin{abstract}
The aim of the research was to assess the adhesion of the powder flame sprayed coatings to the previously prepared substrate. The spraying tests were carried out using Rototec 51000 base powders which was Ni-Al-Mo alloys, then coated with an outer coating made of Rototec 19404, which is an alloy Fe-Cr-Co-Mo.

The coatings were tested for adhesion in accordance with the PN-EN ISO 14916: 2017 standard and also topography tests of sprayed coatings using scanning electron microscopy.
\end{abstract}

Introduction

The dynamic development of technology in the last few decades has put a new challenge in front of the spraying technology - the process of applying coatings which will not have a significant thermal effect on the substrate was sought. The powder flame spraying process allowed to limit thermal stresses in the substrate, and consequently enabled the coating of brittle (ceramics, glass) or low-melting (polymers) materials. The mechanism of coating formation in the powder flame spraying process differs from the mechanisms which take place in conventional thermal spraying methods. In most technologies, the main driving force that guarantees the formation of the coating is an increased thermal energy. In the powder flame spraying method, the amount of thermal energy has been minimized. The coating is created as a result of work carried out at the expense of the kinetic energy of the stream of particles colliding with the surface of the element. The sprayed material and the substrate material are not melted, and also in many cases are not plasticized.

The primary goal of welding technology is to obtain the highest possible properties at the lowest cost. The increased adhesion of powder flame sprayed coatings will reduce the costs of both new parts and the regeneration of already used parts. Cold sprayed coating thermal barriers are used in very many cases, e.g. on substrates in electronics, spark plugs, isolating turbine components or resistant to high temperatures and heatstroke of the combustion chamber of aircraft engines $[1 \div 5]$.

\section{Purpose and course of the research}

The aim of the conducted research was to assess the adhesion of the sprayed coatings to the previously prepared substrate. Powder flame spraying technology was used. The influence of the powder flow rate on the obtained adhesion values was taken into account. Tests of the adhesion of coatings sprayed to the substrate were made on cylindrical samples.

The spraying tests were carried out with the use of Rototec 51000 undercoat powder, which was a Ni-Al-Mo alloy, subsequently coated with an operational coating made of Rototec 19404, which is an Fe-Cr-Co-Mo alloy. The coatings were sprayed on rollers made of $\mathrm{S} 235 \mathrm{~N}$ steel with the dimensions shown in figure 1 . The working surface of the roller was marked with a red line.

The powder manufacturer reports that the Rototec 19404 powder is a metallic powder for making wear resistant coatings on all types of metals, except pure copper and magnesium.

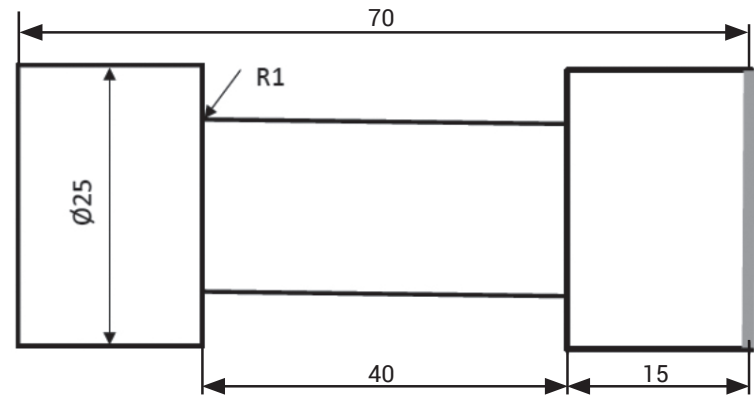

Fig. 1. Dimensions of the shafts used for testing 
Used for example for. shaft sleeves, crankshafts, press rods, plunger pistons and places under the bearings on shafts.

Whereas the Rototec 51000 is a metallic undercoat powder based on Ni-Al-Mo dedicated for powder flame spraying technology. According to the manufacturer, the hardness of the coating is $170 \mathrm{HV}$.

The CastoDyn DS 8000 acetylene-oxygen burner with the SSM10 burner tip was used for the tests. The temperature of the spraying process was controlled and was below $300^{\circ} \mathrm{C}$. The temperature was measured by an industrial pyrometer after applying the undercoat layer and just after the spraying process. The technological conditions of the powder flame spraying process of the undercoat and working layer for cylindrical samples made of $\mathrm{S} 235 \mathrm{~N}$ steel are shown in Table I.

Table I. Technological conditions for cold spraying of the undercoat and working layer on $\mathrm{S} 235 \mathrm{~N}$ steel cylindrical samples

\begin{tabular}{|c|c|}
\hline Oxygen pressure [bar] & 4 \\
\hline Acetylene pressure [bar] & 0,7 \\
\hline Additional transporting gas & - \\
\hline Distance of the burner from the ground [mm] & 200 \\
\hline Number of passes (bonding layer) & 1 \\
\hline Thickness of the bonding layer [mm] & 0,06 \\
\hline Number of passes (working layer) & 5 \\
\hline Thickness of the working layer [mm] & 0,84 \\
\hline
\end{tabular}

Before the spraying process, the working surfaces of the rollers were cleaned in a shot peening operation with corundum particles.

The adhesion test of sprayed coatings was determined by using the tearing method in a static tensile test in accordance with PN-EN ISO 14916:2017 [6]. The tearing method uses a static tensile test to determine the adhesion of the coatings. The face of cylindrical samples covered with a working coating was glued to the counter-sample with Loctite EA 3430 epoxy adhesive with a tensile strength of $36 \mathrm{MPa}$. The samples were placed in a testing machine and subjected to static stretching until their rupture. The tensile test results allowed to determine the value of the peel force from the substrate and to calculate the adhesion of the sprayed coating.

\section{Test results analysis}

The powder flame spraying tests were carried out with the use of undercoat powder, which was a Ni-Al-Mo alloy, subsequently coated with an operational coating made of Rototec 19404, which is an Fe-Cr-Co-Mo alloy. The performed metallographic examinations revealed that on the surface of $S 235 \mathrm{~N}$ steel there were two coatings: undercoat layer (B) and external coating (working)(A)(Fig. 2).

The low temperature of the spraying process resulted in a minimal thermal effect on the steel substrate. The average thickness of the sprayed layer was $900 \mu \mathrm{m}$.

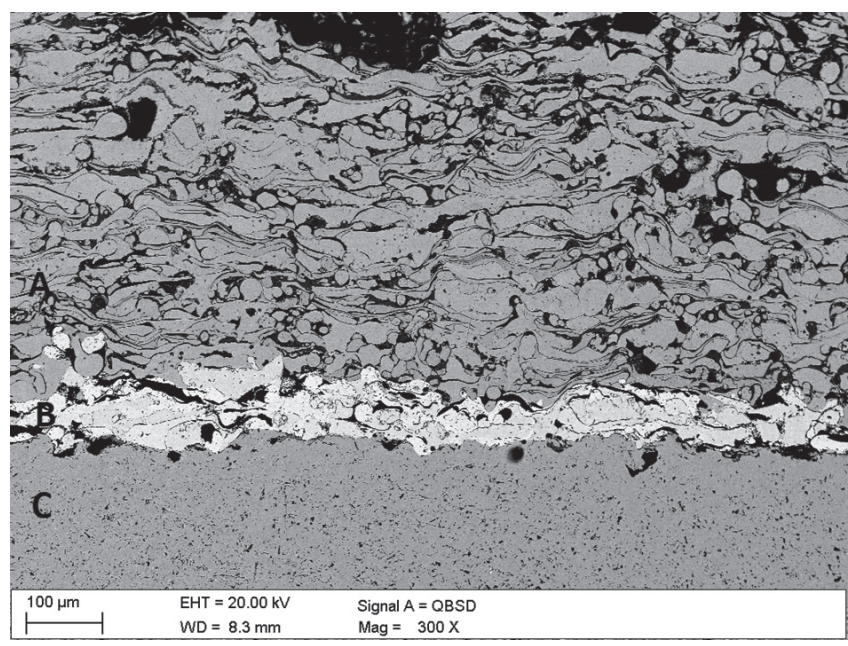

Fig. 2. View of the sprayed coating (series 1 ): $A$ - the structure of the outer coating (working), B - the structure of the undercoat layer, $\mathrm{C}$ - the structure of the native material

Using the scanning electron microscope, analysis of the chemical composition of the undercoat layer and the external coating was performed, which confirmed the chemical composition of the undercoat layer being the Ni-Al-Mo alloy (Fig. 3b). However, in the case of the external coating, the chemical composition was slightly different from the composition declared by the manufacturer (Fig. 3a). According to the manufacturer, the powder was Fe-Cr-Co-Mo alloy, according to the analysis of the chemical composition it was a Fe-Cr alloy with a low content of Si and Co. The lack of Mo in the working coat probably resulted from careless mixing of the powder before the spraying process.

The adhesion to the substrate of the sprayed coatings was determined based on the static tensile test until decohesion of the coating. It showed that the adhesion of the coatings

Table II. Results of the static tensile test of the powder flame sprayed coatings

\begin{tabular}{|c|c|c|c|c|c|c|}
\hline $\begin{array}{l}\text { Designation } \\
\text { of the sample }\end{array}$ & $\begin{array}{l}\text { Bonding } \\
\text { layer }\end{array}$ & $\begin{array}{l}\text { Powder flow rate (setting } \\
\text { according to instructions) }\end{array}$ & $\begin{array}{l}\text { Breaking force } \\
\text { [N] }\end{array}$ & $\begin{array}{c}\text { Adhesion } \\
\text { of the coating [MPa] }\end{array}$ & $\begin{array}{l}\text { Average coating } \\
\text { adhesion [MPa] }\end{array}$ & $\begin{array}{l}\text { Standard } \\
\text { deviation }\end{array}$ \\
\hline 1.1 & \multirow{6}{*}{$\begin{array}{l}\text { Rototec } \\
51000\end{array}$} & \multirow{3}{*}{3} & 5300 & 8.61 & \multirow{3}{*}{9.21} & \multirow{3}{*}{2.73} \\
\hline 1.2 & & & 7000 & 11.37 & & \\
\hline 1.3 & & & 4700 & 7.64 & & \\
\hline 2.1 & & \multirow{3}{*}{4} & 7200 & 11.70 & \multirow{3}{*}{14.14} & \multirow{3}{*}{3.33} \\
\hline 2.2 & & & 10100 & 16.41 & & \\
\hline 2.3 & & & 8800 & 14.30 & & \\
\hline
\end{tabular}



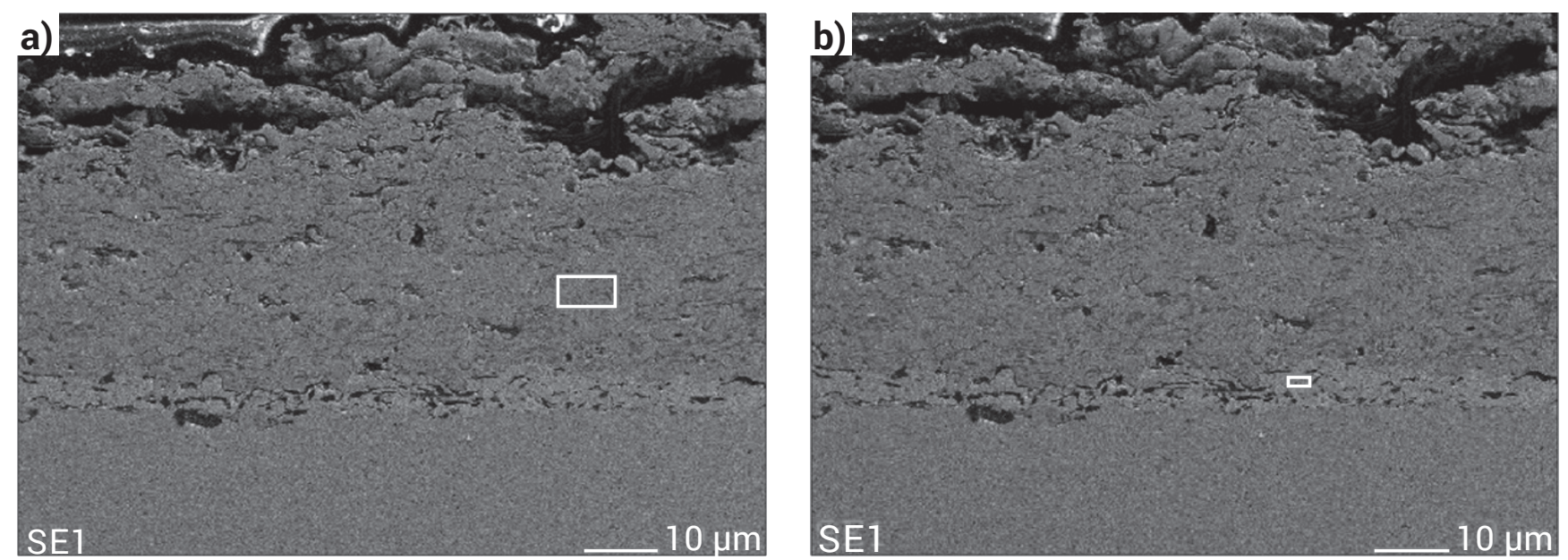

\begin{tabular}{|c|c|}
\hline Element & Wt \% \\
\hline OK & 5,68 \\
\hline SiK & 2,42 \\
\hline CrK & 15,17 \\
\hline FeK & 75,15 \\
\hline CoK & 1,58 \\
\hline
\end{tabular}

\begin{tabular}{|c|c|}
\hline Element & Wt \% \\
\hline OK & 3,84 \\
\hline AlK & 10,70 \\
\hline MoL & 4,69 \\
\hline NiK & 80,78 \\
\hline
\end{tabular}
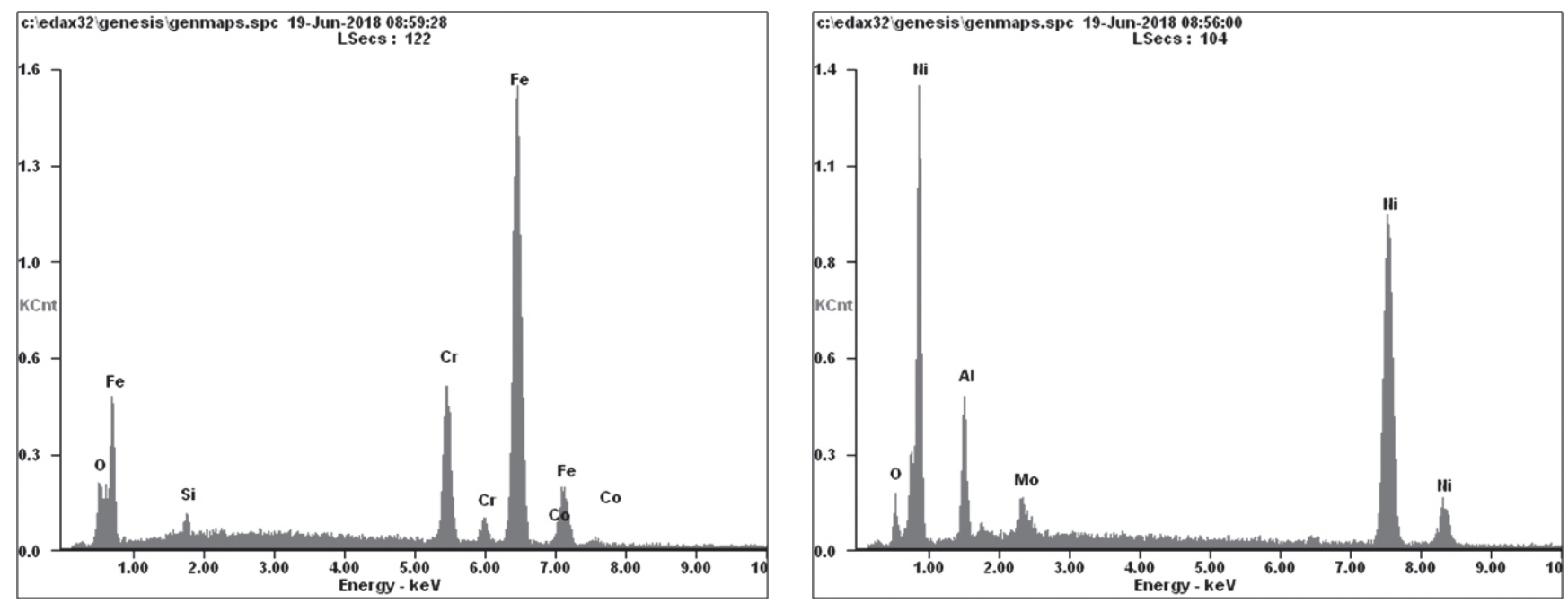

Fig. 3. Microanalysis of the chemical composition of sample 1: a) the outer coating (working), b) the undercoat layer

depended on the flow rate of the powder. The adhesion to the substrate was higher for the powder flow rate of 4 (setting according to the instructions) and was $14 \mathrm{MPa}$. In the case of a lower powder flow rate (3-setting according to the instructions) the adhesion was lower and amounted to $9 \mathrm{MPa}$. The results are shown in Table II. In [2], coatings sprayed with identical technology, identical undercoat powder being a $\mathrm{Ni}$ -Al-Mo alloy and a slightly different working layer, were tested. These layers were characterized by a much lower adhesion to the substrate of $6.5 \mathrm{MPa}$. These layers were made with an even lower powder flow rate (setting 2 according to the instructions), which may indicate a high impact of the powder flow rate on the adhesion of the layer to the substrate [2].

During tests of adhesion to the substrate of sprayed coatings, the assemblies lost their cohesion due to delamination of the external layer from the undercoat layer (Fig. 4).

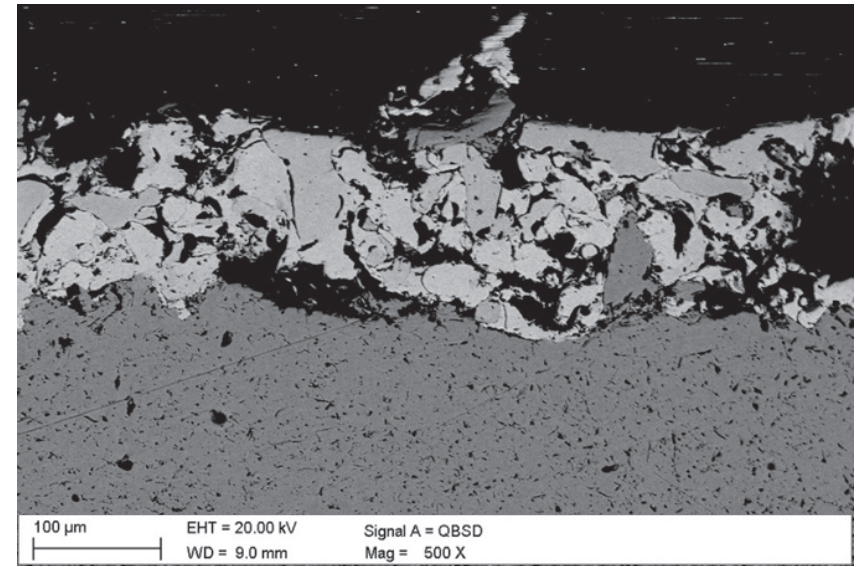

Fig. 4. Microstructure of sample 1.2 after adhesion tests 


\section{Conclusions}

1. Powder flame spraying with Rototec 19404 powder on the undercoat layer made of Rototec 51000 powder allowed to obtain coatings with a thickness of approx. $900 \mu \mathrm{m}$ on a steel substrate.

2. The rate of powder flow affects the adhesion of the layer to the substrate. Higher adhesion to the substrate was characterized by coatings made with a higher powder flow rate.

\section{References}

[1] A. Klimpel, Napawanie i natryskiwania cieplne. Technologie, WNT Warszawa (2000).

[2] M. Adamiak, A. Czupryński, J. Górka, B. Tomiczek, Testing of Flame Sprayed Al2O3 Matrix Coatings Containing TiO2, Archives of Metallurgy and Materials (2016), $\mathrm{nr}$ 3, 1363-1370.

[3] F. Hirotaka, O. Nobutada, A study of adhesive strength of cold spray coatings, Advances in Technology and Applications (2004), 329-334

[4] A. Czupryński, A. Ozgowicz, Analiza właściwości powłokowych barier cieplnych natryskiwanych płomieniowo, Welding Technology Review (2014), vol. 86(12), 9-18

[5] C. Moreno-Tellez, I. Perez-Rodriguez, L. Quintero-Sanchez, Influence of deposit parameters on the adhesion of Ni-Al-Mo coatings by thermal spray, Materials Engineering (2015), vol. 17(2), 101-109.

[6] PN-EN ISO 14916:2017 Natryskiwanie cieplne - określanie przyczepności metodą odrywania. 